\title{
Injury Prevention: A Public Health Concern for India
}

\author{
R Lakhan ${ }^{1}$
}

${ }^{1}$ Doctoral Candidate in Epidemiology, Jackson State University, USA

\section{Chief Editor}

\section{Dr. Indrajit Banerjee}

\section{Technical Editor}

Dr. Indrajit Banerjee

Formatting Editor

Dr. Indrajit Banerjee

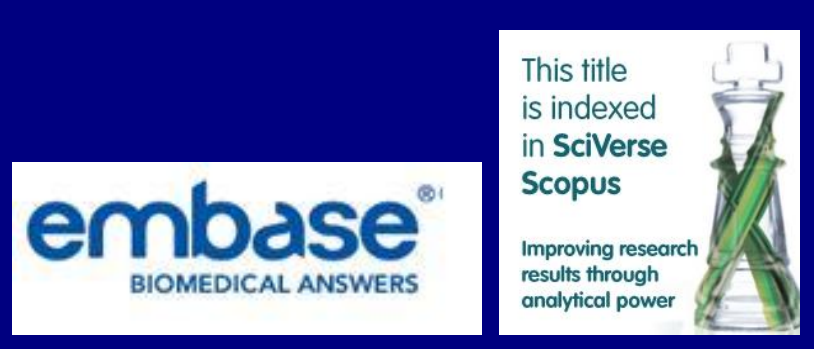

\section{Letter to the Editor}

\section{Corresponding Author:}

Ram Lakhan, BMR, MS

Doctoral Candidate in Epidemiology

School of Health Science, College of Public Service

Jackson State University, 350

West Woodrow Wilson Drive

Jackson, MS 39213

Email Id: ramlakhan15@gmail.com

\section{Dear Editor,}

I read the article with great interest by Pal R, Injury Epidemiology: The Neglected Chapter, published in Nepal Journal of Epidemiology in $2012^{1}$. This topic is highly relevant for India. Injury prevention is an important and integral part of public health. According to the most comprehensive definition by Winslow 1920, public health is about to prevent diseases, prolonging life, and promoting health and efficiency ${ }^{2}$ cannot be achieved unless strong efforts are made to control injuries. The result of strong public health initiatives life expectancy has been increased by 25 years since 1900 in developed nation USA. The control of intentional and unintentional injuries are one of the major contributing factor of this gain ${ }^{2}$.

According to the World health Organization, injuries lead 5.8 million deaths every year across the world. Every 5 seconds someone in world will lose his /her life as result of injury $^{3}$. Presently, they account for $9 \%$ of global mortality. More than $90 \%$ of deaths that results from injuries occur in the Low and Middle Income Countries ${ }^{3}$. The worldwide major cause of injuries are shown in figure $1^{3}$.

Figure 1: Worldwide causes of injuries (\%).

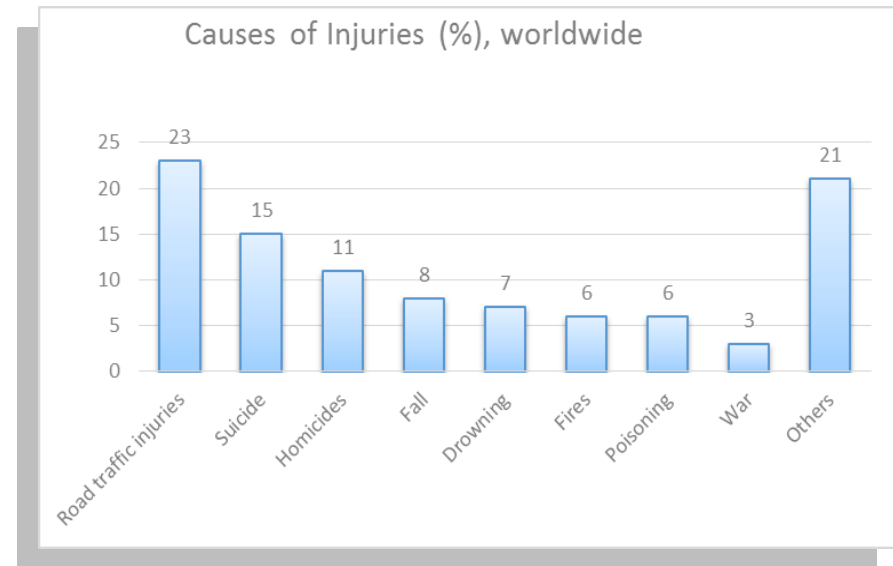

Source: Global burden of disease: 2004

Often injuries lead to a catastrophic impact on individuals and their families. Injuries are one of the major environmental determinants of morbidity, mortality, disability and social disadvantage/disadvantages in India 4 . The literature review presented in Gururaj $2008^{5}$ explains that road traffic injuries are the top contributing factor among all other injury related factors in rural and urban 
India. The poor implementation of traffic rules \& regulations, heterogeneous mixed traffic, poorly designed roads, traffic vehicles, increasing speed, poor use of protective device such as helmet, drinking and driving, poor visibility, and poor trauma care are a major concern in reducing the prevalence of injuries and related outcome ${ }^{5}$. Looking at the magnitude of the problems, strong public health emphasis is needed in the areas of research, policy development, community education and awareness, and the health care system in India.

\section{References}

1. Pal R. Injury Epidemiology: The Neglected Chapter. Nepal Journal of Epidemiology 2012; 2 (4): 216-18.

2. Turnock BJ. What is Public Health? In: Public Health, What It Is and How It Works. $5^{\text {th }}$ ed. Burlington: Jones \& Barlett Learning, 2012, pp 1-45.

3. World Health Organization. Injuries and Violence the Facts. [Online] 2013 [cited 2013 Aug 02]. Available from: URL: http://whqlibdoc.who.int/publications/2010/9789 241599375_eng.pdf

4. Gururaj G. Epidemiology of traumatic brain injuries: Indian scenario. Neurological research 2002; 24 (1): 24-28.

5. Gururaj G. Road traffic deaths, injuries and disabilities in India: current scenario. National Medical Journal of India 2008; 21(1): 14-20.

\section{Article Information}

\section{Article history}

\begin{tabular}{|l|l|}
\hline Received & $12^{\text {h }}$ August 2013 \\
\hline Received in revised form & $7^{\text {th }}$ September 2013 \\
\hline Accepted & $22^{\text {nd }}$ September 2013 \\
\hline
\end{tabular}

